\title{
Inhibition of surgical trauma- enhanced peritoneal dissemination of tumor cells by human catalase derivatives in mice.
}

\section{AUTHOR(S):}

Nishizaki, Chika; Nishikawa, Makiya; Yata, Tomoya; Yamada, Toshiyuki; Takahashi, Yuki; Oku, Masahide; Yurimoto, Hiroya; Sakai, Yasuyoshi; Nakanishi, Kenji; Takakura, Yoshinobu

\section{CITATION:}

Nishizaki, Chika ... [et al]. Inhibition of surgical trauma-enhanced peritoneal dissemination of tumor cells by human catalase derivatives in mice.. Free radical biology \& medicine 2011, 51(3): 773-779

\section{ISSUE DATE:}

2011-08-01

URL:

http://hdl.handle.net/2433/143690

\section{RIGHT:}

(C) 2011 Elsevier Inc:; This is not the published version. Please cite only the published version.; この論文は出版社版でありません。引用の際に は出版社版をご確認ご利用ください。 


\section{Inhibition of surgical trauma-enhanced peritoneal dissemination of tumor cells by human catalase derivatives in mice}

Chika Nishizaki ${ }^{a}$, Makiya Nishikawa ${ }^{a}$, Tomoya Yata ${ }^{a}$, Toshiyuki

Yamada $^{a}$, Yuki Takahashi ${ }^{\mathrm{a}}$, Masahide Oku ${ }^{\mathrm{b}}$, Hiroya Yurimoto ${ }^{\mathrm{b}}$, Yasuyoshi Sakai $^{\text {b }}$, Kenji Nakanishi ${ }^{\mathrm{c}}$, Yoshinobu Takakura ${ }^{\mathrm{a}}$

a: Department of Biopharmaceutics and Drug Metabolism, Graduate School of

Pharmaceutical Sciences, Kyoto University, Sakyo-ku, Kyoto 606-8501, Sakyo-ku,

Japan

${ }^{\mathrm{b}}$ : Division of Applied Life Sciences, Graduate School of Agriculture, Kyoto University,

Sakyo-ku, Kyoto 606-8502, Japan

': Department of Immunology and Medical Zoology, Hyogo College of Medicine,

Nishinomiya, Hyogo 663-8501, Japan

Correspondence to: Makiya Nishikawa, Ph.D., Department of Biopharmaceutics and

Drug Metabolism, Graduate School of Pharmaceutical Sciences, Kyoto University,

Sakyo-ku, Kyoto, Japan.

Phone: +81-75-753-4580; Fax: +81-75-753-4614; E-mail: makiya@pharm.kyoto-u.ac.jp 


\section{Abstract}

Surgical trauma, which is inevitably associated with the surgical removal of cancer, has been reported to accelerate tumor metastasis. The close association of reactive oxygen species with the trauma and tumor metastasis supports the possibility of using antioxidants for the inhibition of metastasis. To inhibit surgical trauma-enhanced peritoneal dissemination, human catalase (hCAT) derivatives, i.e., hCAT-nona-arginine peptide (hCAT-R9) and hCAT-albumin binding peptide (hCAT-ABP), were designed to increase the retention time of the antioxidant enzyme in the abdominal cavity after intraperitoneal administration. Both ${ }^{125}$ I-labeled $\left({ }^{125} \mathrm{I}-\right)$ derivatives showed significantly prolonged retention in the cavity than ${ }^{125}$ I-hCAT. Cauterization of the cecum of mice with a hot iron, an experimental model of surgical trauma, induced abdominal adhesions. In addition, cauterization followed by colon 26 tumor cell inoculation increased lipid peroxidation in the cecum and mRNA expression of molecules associated with tissue repair/adhesion and inflammation in the peritoneum. hCAT derivatives significantly suppressed the increased mRNA expression. The cauterization also increased the number of tumor cells in the abdominal organs, and the number was significantly reduced by hCAT-R9 or hCAT-ABP. These results indicate that hCAT-R9 and hCAT-ABP, both of which have a long retention time in the peritoneal cavity, can be effective in inhibiting surgery-induced peritoneal 
metastasis.

Keywords: recombinant human catalase; surgical trauma; tumor metastasis;

reactive oxygen species 


\section{Introduction}

Much effort has been made to reduce the recurrence and metastasis of cancer after its surgical removal. However, recurrence and metastasis remain the major cause of cancer death [1].

Surgical removal, which is a pivotal treatment for most solid cancers including gastrointestinal carcinoma and ovarian carcinoma, has been suspected to facilitate cancer cell metastasis. This speculation has been supported by several animal studies, in which surgical stress aggravated tumor metastasis [2-5]. Although the mechanism whereby surgical stress enhances tumor metastasis is not fully understood, surgery-induced inflammation and subsequent wound healing have been considered to contribute to the facilitation of tumor metastasis [6,7]. In the processes of inflammation and wound healing, the expression of a variety of proinflammatory cytokines and growth factors is upregulated, which leads to increased production of extracellular matrix (ECM) components. Spilled tumor cells easily adhere to abdominal organs because of abundant ECM components and upregulated adhesion molecules. Then, the environment being rich with growth and angiogenic factors accelerates the proliferation of tumor cells and the formation of new blood vessels to form metastases. Thus, most, if not all, the steps of metastatic tumor growth, such as adhesion to the peritoneum and abdominal organs, proliferation and angiogenesis, are promoted by surgical trauma and the subsequent tissue repair.

Reactive oxygen species (ROS) are involved in both inflammation and tissue repair, and sublethal levels of ROS have been reported to aggravate tumor metastasis [8]. Therefore, eliminating ROS generated by surgical removal of a primary tumor could be an effective 
approach to inhibiting postoperative peritoneal metastasis. Among ROS, hydrogen peroxide has the longest half-life and plays a role as a second messenger that directly activates several transcription factors, including hypoxia inducible factor-1 [9] and nuclear factor $\kappa \mathrm{B}[10]$.

Catalase is the enzyme that catalyzes the decomposition of hydrogen peroxide. Recent studies in experimental peritoneal metastasis mouse models have reported that tumor metastasis is efficiently inhibited by catalase derivatives with prolonged retention in the peritoneal cavity $[11,12]$. We have developed cytophilic derivatives of human catalase (hCAT) by fusing nona-arginine peptide (R9) or three repeats of arginine-glycine-aspartic acid and found that they were effective in inhibiting the adhesion of tumor cells to mouse aortic endothelial cells [13].

These results suggest the possibility that hCAT derivatives are effective in inhibiting surgery-induced tissue adhesion and tumor metastasis. However, lack of appropriate experimental models of surgical trauma has made it difficult to evaluate this hypothesis. Therefore, in this study, a new surgery-induced abdominal adhesion model was developed in mice and used to evaluate the effects of hCAT derivatives on surgery-induced inflammation and peritoneal metastasis. In addition to hCAT and hCAT-R9, hCAT fused with an albumin binding peptide (ABP) [14] was designed as another novel derivative with a long retention in the peritoneal cavity through binding to exuded serum albumin. The properties of hCAT-ABP were initially examined and the effects of hCAT derivatives on surgery-induced peritoneal metastasis of tumor cells were investigated in our surgery-induced abdominal adhesion model. 


\section{Materials and methods}

\section{Chemicals}

Roswell Park Memorial Institute (RPMI) 1640 medium and Hank's balanced salt solution

(HBSS) were obtained from Nissui Pharmaceutical (Tokyo, Japan). Fetal bovine serum (FBS)

was obtained from GIBCO-Invitrogen (Carlsbad, CA, USA). Na ${ }^{125}$ aqueous solution in $0.1 \mathrm{M}$ $\mathrm{NaOH}(\mathrm{NEZ033,} \mathrm{370MBq/ml)} \mathrm{was} \mathrm{purchased} \mathrm{from} \mathrm{Perkin-Elmer} \mathrm{Life} \mathrm{Sciences} \mathrm{(Boston,} \mathrm{MA,}$ USA). Mouse and human serum albumins and bovine immunoglobulin $\mathrm{G}$ were purchased from Sigma-Aldrich Japan (Tokyo, Japan). All other chemicals were of the highest grade commercially available.

\section{Animals}

Male Institute for Cancer Research (ICR) mice (4-week-old), male BALB/c mice (4-week-old) and male C57BL/6 mice (4-week-old) were purchased from Japan SLC, Inc. (Shizuoka, Japan) and maintained on a standard food and water diet under conventional housing conditions. The protocols for the animal experiments were approved by the Animal Experimentation Committee of the Graduate School of Pharmaceutical Sciences of Kyoto University.

\section{Cell cultures}

Colon26/Luc, a clone of murine colon carcinoma colon26 that stably expresses firefly luciferase [11], were grown in RPMI 1640 medium supplemented with $10 \%$ heat-inactivated FBS, 
$0.15 \% \mathrm{NaHCO} 3,100 \mathrm{units} / \mathrm{ml}$ penicillin and $100 \mu \mathrm{g} / \mathrm{ml}$ streptomycin at $37^{\circ} \mathrm{C}$ in humidified air containing $5 \% \mathrm{CO}_{2}$. B16-BL6 cells, clones of murine melanoma, were grown as reported previously [11].

\section{Preparation of human catalase derivatives}

hCAT and hCAT-R9 were obtained as reported previously [13]. hCAT-ABP was designed by replacing the C-terminal 11 amino acid residues (SHLAAREKANL) of hCAT with an ABP having the amino acid sequence GGGSQRLMEDICLPRWGCLWEDDF [14]. Double stranded oligonucleotide corresponding to $\mathrm{ABP}$ (forward sequence, 5 -ggaggaggtagtcaaagattgatggaagacatttgcttgcccagatggggatgcttgtgggaagacgacttc-3`) was obtained by PCR-amplification with two oligonucleotides (5 -tccccgcgggaggaggtagtcaaagattgatggaagacatttgcttgcccagatgg-3` and 5 '-gctctagagctcagaagtcgtcttcccacaagcatccccatctgggcaagcaaatgtc-3`) purchased from

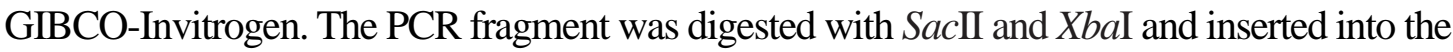
SacII-SpeI site of hCAT expressing pNT40 vector to construct the hCAT-ABP expressing plasmid vector. hCAT-ABP was obtained similarly as hCAT and hCAT-R9 using a Pichia pastoris expression system. Recombinant catalase derivatives were purified as described previously [13], and the purity was identified by SDS-PAGE stained with Coomassie brilliant blue. The activity of hCAT, hCAT-R9 and hCAT-ABP was 33,800 to 37,900, 21,800 to 44,200 and 9,000 to 68,300 units/mg protein, respectively [15]. The differences in the activity would be 
due to the denaturation of the samples during the expression and/or purification processes. In vivo effects of hCAT derivatives on mRNA expression, intraabdominal adhesion and dissemination of tumor cells were evaluated using hCAT derivatives with high specific enzymatic activities: 33,800, 68,300 and 21,800-40,000 for hCAT, hCAT-ABP and hCAT-R9, respectively. The enzymes were stored in a $50 \%$ glycerol solution at $-20^{\circ} \mathrm{C}$ until required and they were stable under these conditions for at least for 12 months. The buffer was replaced with saline by ultrafiltration for animal studies.

\section{Measurement of circular dichroism}

Circular dichroism (CD) spectra were recorded on a JASCO-820-type spectropolarimeter (JASCO, Tokyo, Japan) at $4^{\circ} \mathrm{C}$. For calculation of the mean residue ellipticity [ $\left.\theta\right]$, the molecular mass of the hCAT derivatives was assumed to be $240 \mathrm{kDa}$ [16]. Far-UV (wavelength 200-250 $\mathrm{nm}) \mathrm{CD}$ spectra were recorded at a protein concentration of $0.2 \mathrm{mg} / \mathrm{ml}$ in a $50 \%$ glycerol solution.

\section{Albumin affinity assay}

The binding affinity of hCAT derivatives to albumin or other proteins was determined as described previously [17]. Briefly, $2 \mu \mathrm{g}$ mouse serum albumin, human serum albumin or bovine immunoglobulin $\mathrm{G}$ was added to each well of $96-$ well plates at a volume of $100 \mu 1 /$ well and incubated overnight at $4^{\circ} \mathrm{C}$. The plates were blocked with phosphate buffered saline (PBS, pH 
7.0) containing $0.5 \%$ ovalbumin and $0.05 \%$ Tween- 20 for $60 \mathrm{~min}$ at room temperature. hCAT or hCAT-ABP serially diluted in PBS (pH 7.0) was added to the immobilized albumin at a volume of $100 \mu \mathrm{l} /$ well and incubated for $90 \mathrm{~min}$ at $25^{\circ} \mathrm{C}$. Unbound hCAT derivatives were removed by washing wells with PBS containing $0.05 \%$ Tween-20. Then, rabbit anti-catalase antibody was added to each well and incubated for $60 \mathrm{~min}$ at room temperature. Excess antibody was removed by washing, and goat anti-rabbit Fab'2-horseradish peroxidase (HRP) was added and incubated for $60 \mathrm{~min}$ at $25^{\circ} \mathrm{C}$. Bound $\mathrm{HRP}$ was detected with a tetramethylbenzidine/hydrogen peroxide solution. After $20 \mathrm{~min}$, the reaction was quenched by the addition of $1 \mathrm{M}$ phosphoric acid. The absorbance at $450 \mathrm{~nm}$ was read at a reference wavelength of $590 \mathrm{~nm}$.

\section{${ }^{125}$ I labeling}

hCAT derivatives were radiolabeled with ${ }^{125}$ I using the chloramine-T method [18]. A $90 \mu 1$ volume of sample solution $(200 \mu \mathrm{g} / \mathrm{ml})$ was mixed with $10 \mu \mathrm{l} 0.5 \mathrm{M}$ phosphate buffer $(\mathrm{pH} 7.4)$ and $3 \mu \mathrm{l}\left[{ }^{125} \mathrm{I}\right] \mathrm{NaI}$ solution. Then, $10 \mu \mathrm{l}$ chloramine-T diluted in $0.1 \mathrm{M}$ phosphate buffer $(\mathrm{pH} 7.4)$ was added, and the mixture was vortexed for $30 \mathrm{sec}$ and incubated for $10 \mathrm{~min}$ at room temperature. Finally, $10 \mu 1$ sodium metabisulfite solution $(2.5 \mathrm{mM})$ was added and vortexed for $30 \mathrm{sec}$. The solution was applied to a PD-10 column (GE healthcare, Tokyo, Japan) and eluted with $0.25 \mathrm{M}$ phosphate buffer ( $\mathrm{pH} 7.4$ ) containing $0.2 \%$ BSA. The eluent was collected in plastic tubes and the radioactivity was measured in a well-type NaI-scintillation counter 
(ARC-500, Aloka, Tokyo, Japan). Appropriate fractions were taken and stored at $-20^{\circ} \mathrm{C}$ until required for use.

Tissue distribution of ${ }^{125} I-h C A T$ derivatives after intraperitoneal injection

Each ${ }^{125}$ I-labeled hCAT derivative was injected intraperitoneally into male ICR mice at a dose of $0.5 \mathrm{mg} / \mathrm{kg}$ mouse. At appropriate intervals after injection, ascitic fluid was collected by injecting 5ml PBS. The peritoneum, liver, kidneys, and gastrointestinal tract were collected and washed with saline. The radioactivity of the tissue samples was counted as described above.

\section{Surgical trauma mouse model}

Male BALB/c mice or male C57BL/6 mice were anaesthetized with isoflurane. An

approximately $10 \mathrm{~mm}$ long anterior midline incision was made through the abdominal wall and peritoneum. The cecum was gently isolated from the abdominal cavity and cauterized for $1 \mathrm{sec}$ using an electrical soldering iron (Mypen alpha, HAKKO, Osaka, Japan). The cecum was returned to its normal position and the incision was closed with silk sutures. Administration of hCAT derivatives ( 500 units in $0.1 \mathrm{ml}$ saline) was carried out immediately after closure by intraperitoneal injection. Five minutes after the surgery, $1 \times 10^{5}$ colon26/Luc cells (BALB/c mice) or B16-BL6 cells (C57BL/6 mice) in $0.1 \mathrm{ml} \mathrm{HBSS}$ were inoculated into the cavity by intraperitoneal injection. 
At 3 days after inoculation of tumor cells, the peritoneum, liver, gastrointestinal tract, and greater omentum were removed. The tissues were homogenized in a lysis buffer $(0.05 \%$ TritonX-100, 0.1 M Tris, $\mathrm{pH} 7.8$ ) followed by centrifugation at $13,000 \times \mathrm{g}$ for $10 \mathrm{~min}$. Then $10 \mu \mathrm{l}$ of the supernatant was mixed with $50 \mu 1$ luciferase assay buffer (Picagene, Toyo Ink, Tokyo, Japan) and the light produced was measured in a luminometer (Lumat LB 9507, EG\&G Berthold, Bad Wildbad, Germany).

mRNA quantification

Total RNA was isolated using Sepasol RNAI super (Nacalai Tesque, Kyoto, Japan). The changes in the mRNA level of plasminogen activator inhibitor-1 (PAI-1), transforming growth factor- $\beta 1$ (TGF- $\beta 1$ ), intracellular adhesion molecule-1 (ICAM-1), vascular endothelium growth factor (VEGF) and tissue necrosis factor $\alpha(\mathrm{TNF}-\alpha)$ were examined using a real-time polymerase chain reaction (RT-PCR). Reverse transcription was performed using a ReverTra Ace ${ }^{\circledR}$ qPCR RT Kit (TOYOBO, Osaka, Japan). For quantitative analysis of mRNA expression, RT-PCR was carried out with total RNA using a Light Cycler instrument (Roche Diagnostics, Basle, Switzerland). The oligonucleotide primers used for amplification were as follows: PAI-1, forward (5'-tcagccettgcttgectcat-3') and reverse (5'-gcatagccagcaccgagga-3'); TGF- $\beta 1$, forward (5`-ttgcttcagctccacagaga-3`) and reverse (5`-tggttgtagagggcaaggac-3`); ICAM-1, forward (5 '-gggaatgtcaccaggaat-3`) and reverse (5`-tcctgagccttctgtaacttg-3`); VEGF, forward (5`-ttcagagcggagaaagcatt-3`) and reverse (5`-gaggaggctccttcctgc-3`); TNF- $\alpha$, forward 
(5`-agccgatgggttgtaccttgtcta-3`) and reverse (5`-tgagatagcaaatcggctgacggt-3`); GAPDH, forward (5 '-ctgccaagtatgatgacatcaacaa-3`) and reverse (5 -accaggaaatgagcttgaca-3`). Amplified products were detected online via intercalation of the fluorescent dye SYBR green (LightCycler-FastStart DNA Master SYBR Green I kit, Roche Diagnostics, Indianapolis, IN, USA). The mRNA expression of the target genes of interest was normalized to the mRNA level of GAPDH.

\section{Measurement of lipid peroxides}

The isolated cecum was homogenized in $1.15 \% \mathrm{KCl}$ solution, centrifuged at 4,000×g, for 10 min, and $200 \mu \mathrm{l}$ of the supernatant was mixed with $25 \mu \mathrm{l}$ 2,6-di-tert-butyl-4-methylphenol ( $5 \mathrm{mM}$ in ethanol) and $200 \mu \mathrm{l}$ orthophosphoric acid (0.2 M). Then, $25 \mu \mathrm{l}$ 2-thiobarbituric acid (TBA) reagent ( $0.11 \mathrm{M} \mathrm{TBA}$ in $0.1 \mathrm{M} \mathrm{NaOH})$ was added, followed by vortexing for $10 \mathrm{sec}$ to allow reaction with malondialdehyde (MDA). After incubation for 45 $\min$ at $90{ }^{\circ} \mathrm{C}$, thiobarbituric acid-reactive substances (TBARS) were extracted with $0.5 \mathrm{ml}$ n-butanol. Then, the TBARS-derived fluorescence was measured in a multilabel counter (excitation at $530 \mathrm{~nm}$, emission at $560 \mathrm{~nm}$, Wallac 1420 ARVO MX-2; Perkin-Elmer Life Sciences Boston, MA, USA). Separately, the protein concentration of the supernatant was assayed using a BCA Protein Assay Kit (Pierce, Rockford, IL, USA). The TBARS values were normalized with regard to the protein content. 
Statistical analysis

Differences were statistically evaluated by one-way analysis of variance (ANOVA) followed by Fisher's LSD for multiple comparisons and by Student's t-test for two groups. P-values of less than 0.05 were considered to be statistically significant. 


\section{Results}

Properties of human catalase derivatives

The properties of hCAT-R9 have already been reported [13]. The SDS-PAGE analysis showed a single band of about $60 \mathrm{kDa}$ (Fig. 1A), which was comparable with the molecular weight of the hCAT monomer and consistent with the estimated molecular weight of hCAT-ABP (about 61 kDa). Fig. 1B shows the far-UV CD-spectra of hCAT and hCAT-ABP. There was no significant difference in the spectra of hCAT and hCAT-ABP, indicating that the fusion of ABP to the C-terminal of human catalase hardly altered the secondary structure. hCAT-ABP was bound to immobilized mouse serum albumin, whereas hCAT was not (Fig. 1C). The binding of hCAT-ABP to the albumin was marked compared with the binding to human serum albumin or bovine immunoglobulin G (Fig. 1D). hCAT-R9 was also bound to immobilized mouse serum albumin, but its binding affinity was lower than that of hCAT-ABP. Its affinity for mouse serum albumin was comparable with that to human serum albumin or immunoglobulin G., suggesting that hCAT-R9 weakly and nonspecifically binds to negatively charged proteins (data not shown),

Retention of human catalase derivatives in the abdomen

The radioactivity in the ascitic fluid, peritoneum, greater omentum, liver, kidneys and gastrointestinal tract was summed and used as an indicator of the retention of ${ }^{125} \mathrm{I}$-hCAT derivatives in the abdomen after intraperitoneal injection. Fig. 2A shows the time course of radioactivity in the abdomen of mice following intraperitoneal injection of ${ }^{125} \mathrm{I}-\mathrm{hCAT}$ 
derivatives. About $67 \%$ of the radioactivity remained $1 \mathrm{hr}$ after injection of ${ }^{125} \mathrm{I}$-hCAT-R9, which was significantly higher than that after injection of ${ }^{125} \mathrm{I}$-hCAT or ${ }^{125} \mathrm{I}$-hCAT-ABP. A high distribution of hCAT-derivatives was observed to the gastrointestinal tract and ascitic fluid (Fig. 2B). At $8 \mathrm{hr}$ after injection, significantly higher radioactivity was detected in the gastrointestinal tract after injection of ${ }^{125}$ I-hCAT-R9 or ${ }^{125}$ I-hCAT-ABP than after ${ }^{125}$ I-hCAT (Fig. 2C). There was no significant radioactivity detected in the thyroid, suggesting that the radioactivity reflects the distribution of ${ }^{125} \mathrm{I}$-hCAT derivatives (data not shown).

\section{Abdominal changes induced by cauterization and tumor inoculation}

The cauterization induced intraabdominal adhesions among the cecum, peritoneum, gastrointestinal tract and adipose tissue (Supplemental figure A,B). To examine the overproduction of ROS by surgical treatment, the level of MDA, a marker for lipid peroxidation, in the cecum was measured on postoperative day 1 . The MDA level of the surgery group was about 5 times higher than that in the non-surgery group (Fig. 3A). The mRNA expression levels of PAI-1, TGF- $\beta 1$, ICAM-1, VEGF and TNF- $\alpha$ in the peritoneum were significantly increased by the surgical treatment (Fig. 3B), suggesting that inflammation and wound healing took place. Intraabdominal metastasis was markedly accelerated and widely disseminated by surgical trauma, especially in the peritoneum, the cauterized cecum and adhesion sites (Supplemental figure C-E). The total number of tumor cells increased about 12-fold on postoperative day 3 (Fig. 3C). A similar difference was also observed on postoperative day 14 (data not shown). 
Effect of $h C A T$ derivatives on mRNA expression and intraabdominal adhesion

Fig. 4 shows the mRNA expression levels in the peritoneum on postoperative day 1 . The mRNA expression levels of PAI-1, TGF- $\beta 1$, ICAM-1, VEGF and TNF- $\alpha$ in the peritoneum were significantly increased by the surgical treatment. The injection of any hCAT derivative at a dose of 500 units/mouse was effective in preventing the surgery-induced increase in the mRNA expression. No significant difference was observed among the groups treated with hCAT or hCAT derivatives.

Inhibition of surgery-enhanced peritoneal dissemination by hCAT derivatives

Fig. 5 shows the number of colon26/Luc cells in abdominal organs 3 days after inoculation. Cauterization of the cecum significantly increased the number of colon26/Luc cells in the cecum and the peritoneum. Administration of hCAT produced a slight but not significant reduction in the number, whereas hCAT-R9 or hCAT-ABP significantly reduced it to about $41 \%$ or $28 \%$, respectively, of that in the saline group. 


\section{Discussion}

Chemically modified catalase derivatives have been reported to have a therapeutic effect on such diseases [19-23]. Despite their usefulness, they are always associated with a potential risk of heterogeneity, reproducibility and reduced enzymatic activity. Instead, genetic modification techniques have been used to avoid these risks. In this study, P. pastoris, which has been used to express a number of proteins [24], was selected as the host to produce human catalase derivatives.

A previous study has reported that hCAT-R9 showed higher affinity for endothelial cells and a greater inhibitory effect on oxidative stress-accelerated adhesion of tumor cells in vitro than unmodified hCAT [13]. The prolonged retention of ${ }^{125}$ I-hCAT-R9 suggests that it can bind to the surface of abdominal organs after intraperitoneal injection. The surface of these organs is lined with mesothelial cells and an electrostatic interaction would be the reason for the long retention of hCAT-R9. When tissues are damaged, negatively charged basal membrane is exposed, so such a change would also become a site for hCAT-R9 binding.

Increasing the effective molecular size is another approach to prolonging the retention of hCAT in the abdominal cavity, because the systemic absorption from the cavity is a function of the size [25]. Serum albumin was selected as a partner because of its abundance and relatively large molecular size. Previous studies have reported that fusing the ABP to drugs with a short half-life improved the retention time in the blood [26]. In contrast to hCAT-R9, which exhibited a nonspecific interaction with the cell surface, hCAT-ABP could distribute to a larger area of the 
abdominal cavity, where it would efficiently degrade ROS. This feature might explain why hCAT-ABP exhibited somewhat higher inhibitory effects than hCAT-R9, although the difference was not statistically significant.

Surgical trauma has been suggested to be an important aggravating factor for tumor metastasis [2-5,11], but its effects on metastasis have received little attention. We developed a surgery-enhanced peritoneal metastasis mouse model according to a recent publication [27]. The tissue damage and intraabdominal adhesions were reproducible when a fixed set of parameters were used. Therefore, this model appears to be a suitable preclinical model to investigate surgical trauma-induced tumor metastasis.

The cauterization induced a variety of changes in the abdominal organs that are typical of damaged tissues [6,7]. The increased mRNA expression of TNF- $\alpha$, TGF- $\beta 1$ and VEGF suggested that the damage started to heal. These factors stimulate the synthesis of ECM and the expression of adhesion molecules, such as ICAM-1. On the other hand, the increased expression of PAI-1 could suppress the degradation of ECM components. Taken together, ECM components accumulate at the wound sites and contribute to tissue repair and remodeling. The present study clearly demonstrates that the surgery-induced changes significantly increase the metastatic growth of tumor cells. Therefore, it is strongly suggested that a postsurgical intraperitoneal environment is highly-favorable for detached and floating tumor cells to produce metastasis.

The inhibition of the mRNA expression by any hCAT derivative used (Fig. 4) indicates 
that the scavenging hydrogen peroxide is a promising way of inhibiting the surgery-induced mRNA overexpression. Similar trends were observed in the number of colon26/Luc cells, but only hCAT-R9 and hCAT-ABP significantly reduced it (Fig. 5). We also obtained similar results using mouse melanoma B16-BL6 cells (Nishizaki et al., unpublished data). A possible reason for this discrepancy is the difference in the timing of these assays: 1 and 3 days after administration for mRNA expression and the number of tumor cells, respectively. hCAT is effective in inhibiting the mRNA expression at a very early time point but, because of its short retention time, it could be less effective in inhibiting metastatic tumor growth at later time points. In surgery-enhanced metastasis and recurrence, the most important process is the adhesion of tumor cells to the abdominal organs. Almost all spilled tumor cells in the cavity were reported to die within three days unless adhesion occurred. Therefore, hCAT derivatives can be considered to reduce the risk of cancer recurrence/metastasis, the major cause of cancer death.

There was high accumulation of ${ }^{125} \mathrm{I}$-hCAT derivatives in the GI tract (Figure 2B, C), whereas significant reduction in the number of colon26/Luc cells was observed in the peritoneum of the hCAT-ABP- or hCAT-R9-treated groups (Figure 5). This apparent discrepancy could be explained by the fact that the peritoneum is one of the typical organs where intraabdominal adhesions are formed (Supplemental figure). In addition, the cauterization could alter the distribution of hCAT derivatives.

In conclusion, hCAT-R9 or hCAT-ABP has been found effective in inhibiting the metastasis of colon26/Luc cells following intraperitoneal injection. No significant differences 
were observed between hCAT-R9 and hCAT-ABP, suggesting that the retention time is important for the increased therapeutic effects of these derivatives. These results indicate that the newly developed hCAT derivatives are promising agents for inhibiting the surgical trauma-enhanced peritoneal metastasis of tumor cells. 


\section{Acknowledgement}

This work is supported by a Grant-in-aid for Scientific Research (B) from the Japan Society for the Promotion of Science (JSPS). 


\section{Abbreviations}

hCAT, human catalase; hCAT-R9, human catalase fused with RRRRRRRRR; hCAT-ABP, human catalase fused with albumin binding peptide; ${ }^{125} \mathrm{I}$-hCAT, ${ }^{125} \mathrm{I}$-labeled human catalase; ECM, extracellular matrix; ROS, reactive oxygen species; ABP, albumin binding peptide; $C D$, circular dichroism; PAI-1, plasminogen activator inhibitor-1; TGF- $\beta 1$, transforming growth factor- $\beta 1$; ICAM-1, intracellular adhesion molecule-1; VEGF, vascular endothelium growth factor; TNF- $\alpha$, tissue necrosis factor- $\alpha$; GAPDH, glyceraldehyde-3-phosphate dehydrogenase; RT-PCR, reverse transcriptional polymerase chain reaction; MDA, malondialdehyde; P. pastoris, Pichia pastoris 


\section{References}

[1] Simmonds PC, Primrose JN, Colquitt JL, Garden OJ, Poston GJ, Rees M. Surgical resection of hepatic metastases from colorectal cancer: a systematic review of published studies. Br J Cancer. 94: 982-999; 2006.

[2] Lee JW, Shahzad MMK, Lin YG, Armaiz-Pena G, Mangala LS, Han HD, Kim HS, Nam EJ, Jennings NB, Halder J, Nick AM, Stone RL, Lu C, Lutgendorf SK, Cole SW, Lokshin AE, Sood AK. Surgical stress promotes tumor growth in ovarian carcinoma. Clin Cancer Res. 15: 2695-2702; 2009.

[3] Lee SW, Gleason N, Blanco I, Asi ZK, Whela RL. Higher colon cancer tumor proliferative index and lower tumor cell death rate in mice undergoing laparotomy versus insufflation. Surg Endosc.16: 36-39; 2002.

[4] Glasner A, Avraham R, Rosenne E, Benish M, Zmora O, Shemer S, Meiboom H, Ben-Eliyahu S. Improving survival rates in two models of spontaneous postoperative metastasis in mice by combined administration of a $\beta$-adrenergic antagonist and a cyclooxygenase-2 inhibitor. J Immunol. 184: 2449-2457; 2010.

[5] Allendorf JD, Bessler M, Horvath KD, Marvin MR, Laird DA, Whelan RL. Increased tumor establishment and growth after open vs laparoscopic bowel resection in mice. Surg Endosc. 12: 1035-1038; 1998.

[6] Coussens LM, Werb Z. Inflammation and cancer. Nature. 420: 860-867; 2002.

[7] Oosterling SJ, van der Bij GJ, van Egmond M, van der Sijp JR. Surgical trauma and 
peritoneal recurrence of colorectal carcinoma. Eur J Surg Oncol. 31: 29-37; 2005.

[8] Nishikawa M. Reactive oxygen species in tumor metastasis. Cancer Lett. 266: 53-59; 2008

[9] Chandel NS, McClintock DS, Feliciano CE, Wood TM, Melendez JA, Rodriguez AM, Schumacker PT. Reactive oxygen species generated at mitochondrial complex III stabilize hypoxia-inducible factor-1 $\alpha$ during hypoxia: a mechanism of $\mathrm{O}_{2}$ sensing. $J$ Biol Chem. 275: 25130-25138; 2000.

[10] Schmidt KN, Amstad P, Cerutti P, Baeuerle PA. The roles of hydrogen peroxide and superoxide as messengers in the activation of transcription factor NF-кB. Chem Biol. 2: 13-22; 1995.

[11] Hyoudou K, Nishikawa M, Kobayashi Y, Mukai S, Ikemura M, Kuramoto Y, Yamashita F, Hashida M. Inhibition of peritoneal dissemination of tumor cells by cationized catalase in mice. J Control Release. 119: 121-127; 2007.

[12] Hyoudou K, Nishikawa M, Ikemura M, Kobayashi Y, Mendelsohn A, Miyazaki N, Tabata Y, Yamashita F, Hashida M. Cationized catalase-loaded hydrogel for growth inhibition of peritoneally disseminated tumor cells. J Control Release. 122: 151-158; 2007.

[13] Yata T, Nishikawa M, Nishizaki C, Oku M, Yurimoto H, Sakai Y, Takakura Y. Control of hypoxia-induced tumor cell adhesion by cytophilic human catalase. Free Radic Biol Med. 47:1772-1778; 2009. 
[14] Dennis MS, Zhang M, Meng YG, Kadkhodayan M, Kirchhofer D, Combs D, Damico LA. Albumin binding as a general strategy for improving the pharmacokinetics of proteins. J Biol Chem. 277: 35035-35043; 2002.

[15] Shi XL, Feng MQ, Shi J, Shi ZH, Zhong J, Zhou P. High-level expression and purification of recombinant human catalase in Pichia pastoris. Protein Expr Purif. 54: 24-29; 2007.

[16] Ma SF, Nishikawa M, Katsumi H, Yamashita F, Hashida M. Liver targeting of catalase by cationization for prevention of acute liver failure in mice. J Control Release. $\mathbf{2}$ : $273-282 ; 2006$.

[17] Nguyen A, Reyes AE II, Zhang M, Mcdonald P, Wong WLT, Damico LA, Dennis MS. The pharmacokinetics of an albumin binding Fab (AB.Fab) can be modulated as a function of affinity for albumin. Protein Eng Des Sel. 19: 291-297; 2006.

[18] Staud F, Nishikawa M, Morimoto K, Takakura Y, Hashida M. Disposition of radioactivity after injection of liver-targeted proteins labeled with ${ }^{111}$ In or ${ }^{125}$ I. Effect of labeling on distribution and excretion of radioactivity in rats. J Pharm Sci. 88: 577-585; 1999.

[19] Nishikawa M, Tamada A, Hyoudou K, Umeyama Y, Takahashi Y, Kobayashi Y, Kumai H, Ishida E, Staud F, Yabe Y, Takakura Y, Yamashita F, Hashida M. Inhibition of experimental hepatic metastasis by targeted delivery of catalase in mice. Clin Exp Metastasis. 21: 213-221; 2004. 
[20] Hyoudou K, Nishikawa M, Kobayashi Y, Umeyama Y, Yamashita F, Hashida M. PEGylated catalase prevents metastatic tumor growth aggravated by tumor removal. Free Radic Biol Med. 41: 1449-1458; 2006.

[21] Ikemura M, Nishikawa M, Hyoudou K, Kobayashi Y, Yamashita F, Hashida M. Improvement of insulin resistance by removal of systemic hydrogen peroxide by PEGylated catalase in obese mice. Mol Pharm. 7: 2069-2076; 2010.

[22] Atochina EN, Balyasnikova IV, Danilov SM, Granger DN, Fisher AB, Muzykantov VR. Immunotargeting of catalase to ACE or ICAM-1 protects perfused rat lungs against oxidative stress. Am J Physiol. 275: 806-817; 1998.

[23] Kozower BD, Christofidou-Solomidou M, Sweitzer TD, Muro S, Buerk DG, Solomides CC, Albelda SM, Patterson GA, Muzykantov VR. Immunotargeting of catalase to the pulmonary endothelium alleviates oxidative stress and reduces acute lung transplantation injury. Nat Biotechnol. 21: 392-398; 2003.

[24] Gerngross TU. Advances in the production of human therapeutic proteins in yeasts and filamentous fungi. Nat Biotechnol. 22: 1409-1414; 2004.

[25] Leypoldt JK, Parker HR, Frigon RP, Henderson LW. Molecular size dependence of peritoneal transport. J Lab Clin Med. 110: 207-216; 1987.

[26] Dennis MS, Jin H, Dugger D, Yang R, McFarland L, Ogasawara A, Williams S, Cole MJ, Ross S, Schwall R. Imaging tumors with an albumin-binding Fab, a novel tumor-targeting agent. Cancer Res. 67: 254-261; 2007. 
[27] Kosaka H, Yoshimoto T, Yoshimoto T, Fujimoto J, Nakanishi K. Interferon- $\gamma$ is a therapeutic target molecule for prevention of postoperative adhesion formation. Nat Med. 14: 437-441; 2008. 


\section{Figure legends}

\section{Fig.1: Characteristics of hCAT derivatives.}

(A) SDS-PAGE analysis of hCAT derivatives stained with Coomassie brilliant blue. Lanes 1 and 4, Precision Protein Unstained Marker (Bio-Rad); lanes 2 and 5, crude hCAT (lane 2) and hCAT-ABP (lane 5); lanes 3 and 6; purified hCAT (lane 3) and hCAT-ABP (lane 6) using glutathione-Sepharose column. (B) Far-UV CD spectra of hCAT derivatives. The protein concentration was $0.2 \mathrm{mg} / \mathrm{ml}$ in $50 \%$ glycerol buffer. (C) Binding of hCAT derivatives to immobilized mouse serum albumin. (D) Binding of hCAT-ABP to immobilized mouse serum albumin, human serum albumin or bovine immunoglobulin G. Key: MSA, mouse serum albumin; HSA, human serum albumin; IgG, bovine immunoglobulin G.

\section{Fig.2: Dissapearance of radioactivity after intraperitoneal injection of ${ }^{125} \mathrm{I}-\mathrm{hCAT}$} derivatives.

(A) Time course of the total ${ }^{125}$ I-radioactivity in the abdominal organs and ascitic fluid of mice after intraperitoneal injection of ${ }^{125} \mathrm{I}$-hCAT, ${ }^{125} \mathrm{I}$-hCAT-R9 and ${ }^{125} \mathrm{I}$-hCAT-ABP $(0.5 \mathrm{mg} / \mathrm{kg}$ weight). Results are expressed as the mean \pm SE of 4 mice. $* P<0.05$ compared with ${ }^{125} \mathrm{I}$-hCAT group at the same time point. (B, C) The tissue distribution of ${ }^{125}$ I-radioactivity at $1 \mathrm{hr}(\mathrm{B})$ or 8 $\mathrm{hr}(\mathrm{C})$ after intraperitoneal injection of ${ }^{125} \mathrm{I}$-hCAT derivatives. Results are expressed as the mean \pm SE of 4 mice. $* P<0.05$ compared with the ${ }^{125}$ I-hCAT group. 
Fig.3: Effect of surgical trauma and intraperitoneal inoculation of colon26/Luc cells.

(A) The level of MDA in the cecum on postoperative day 1. Results are expressed as the mean \pm SE of 4 mice. $* P<0.05$, compared with no treatment (NT) group. (B) The mRNA expression in the peritoneum on postoperative day 1 . Results are expressed as the mean \pm SE of 3 or 4 mice. $* P<0.05$ compared with the no treatment (NT) group; $\quad+P<0.05$ compared with the colon26/Luc group; $\# P<0.05$ compared with the other groups. (C) The total number of colon26/Luc cells in the abdominal organs on postoperative day 3. Results are expressed as the mean \pm SE of 3 (non-surgery) or 5 (surgery) mice. $* P<0.05$ compared with the non-surgery group.

Fig.4: Effect of hCAT derivatives on surgery-enhanced mRNA expression.

The mRNA expression in the peritoneum on postoperative day 1. Results are expressed as the mean \pm SE of 3 or 4 mice. $* P<0.05$ compared with the non-surgery group; $+P<0.05$ compared with the colon26/Luc group; $\# P<0.05$ compared with the other groups.

\section{Fig.5: Effect of hCAT derivatives on surgery-enhanced peritoneal dissemination.}

Colon26/Luc cells were inoculated into the peritoneal cavity $\left(1 \times 10^{5}\right.$ cells $)$ after surgery. On postoperative day 3, the liver, omentum, peritoneum and gastrointestinal tract were isolated and the number of tumor cells was assayed. Results are expressed as the mean \pm SE of 3 to 5 mice. $* P<0.05$, compared with the non-surgery group; $\# P<0.05$, compared with the surgery, saline 
group. 